Review

\title{
Relevance of the Anti-Inflammatory Properties of Curcumin in Neurodegenerative Diseases and Depression
}

\author{
Yousef Tizabi *, Laura L. Hurley, Zakiya Qualls and Luli Akinfiresoye \\ Department of Pharmacology, College of Medicine, Howard University, Washington, DC 20059, \\ USA; E-Mails: laura.hurley@students.mq.edu.au (L.L.H.); quallszm@njms.rutgers.edu (Z.Q.); \\ 1ra28@georgetown.edu (L.A.) \\ * Author to whom correspondence should be addressed; E-Mail: ytizabi@howard.edu; \\ Tel.: +1-202-806-9719, Fax: +1-202-806-4453.
}

External Editors: Sahdeo Prasad and Bharat B. Aggarwal

Received: 21 October 2014; in revised form: 5 December 2014 / Accepted: 8 December 2014 / Published: 12 December 2014

\begin{abstract}
This review is an attempt to summarize our current understanding of curcumin's potential as a neuroprotectant and an antidepressant. This dual property confers a unique advantage to this herbal medication, believed to be devoid of any major side effects, to combat commonly observed co-morbid conditions of a neurodegenerative and a neuropsychiatric disorder. Moreover, in line with the theme of this series, the role of inflammation and stress in these diseases and possible anti-inflammatory effects of curcumin, as well as its interaction with signal transduction proteins as a common denominator in its varied mechanisms of action, are also discussed. Thus, following a brief introduction of curcumin's pharmacology, we present research suggesting how its anti-inflammatory properties have therapeutic potential in treating a devastating neurological disorder (Parkinson's disease = PD) and a debilitating neuropsychiatric disorder (major depressive disorder = MDD). It is concluded that curcumin, or better yet, an analog with better and longer bioavailability could be of important therapeutic potential in PD and/or major depression.
\end{abstract}

Keywords: curcumin; inflammation; depression; Parkinson's disease; neuroprotection 


\section{Curcumin}

Curcumin, a diarylheptanoid, is the principal curcuminoid of the popular South Asian spice turmeric (Curcuma longa), which is a member of the ginger family (Zingiberaceae). Curcumin and turmeric's other two curcuminoids, desmethoxycurcumin and bisdesmethoxycurcumin are natural phenols responsible for the yellow color of turmeric. Indeed, because of its bright-yellow color, curcumin is used as a food coloring as well as food additive. Curcumin can exist in several tautomeric forms, however, the enol form is more stable in the solid phase and in solution [1].

Curcumin's antioxidant [2-4], hepato- and nephroprotectant [5-7], antimicrobial [8,9], anti-inflammatory [10-13] and potential anti-depressant properties [14-19] are well documented. Epidemiological studies have demonstrated that societies that widely use curcumin show reduced incidence of inflammation-influenced and cognitive function diseases such as Alzheimer's disease [20-23]. It has also been suggested that curcumin may reduce the incidence of Parkinson's disease (PD), as some studies have shown an absence of age-related changes in nigral dopaminergic neurons in Indian populations that consume large amounts of curcumin [24-26]. Moreover, as discussed below, numerous in vitro and in vivo studies provide substantial evidence for a protective effect of curcumin against insults that may precipitate PD-like symptoms.

\section{Depression}

\subsection{General Considerations}

Major depression is a disorder with many definitions and manifestations and with a 12-month prevalence rate of $6.3 \%$ to $10.3 \%$ in Western societies [27]. Symptoms may vary, but often include anhedonia, disrupted sleep patterns, lack of motivation, or emotional distress (e.g., anxiety). Although a number of clinically effective treatments are available, a large segment of patients are non-responsive (i.e., exhibit treatment-resistance to first-line interventions: [28,29]). Recent discoveries provide growing support for presence of cellular atrophy and neuronal death in major depressive disorder (MDD) as well as neurotrophic effects associated with antidepressants [30-34]. Thus, converging evidence support neurotrophic effects as a unifying hypothesis for antidepressants efficacy in treating MDD (see [35] for a detailed review). Moreover, activation of the ERKMAPK pathway by antidepressants increases the expression of nuclear CREB, which facilitates the expression of neurotrophic/neuroprotective proteins such as Bcl-2 and brain-derived neurotrophic factor (BDNF). A current hypothesis posits that curcumin alleviates depressive behavior through activation of ERK-Bcl-2-BDNF neurotrophic pathway [36-40], particularly in areas implicated in the pathophysiology of depression (e.g., hippocampus and olfactory system: [41-43]).

\subsection{Depression-Inflammation}

The purpose of inflammation is primarily to remove or inactivate potentially damaging agents or damaged tissues. This response is mediated via one of two cell systems: glia of the central nervous system (CNS), and lymphocytes, monocytes, and macrophages of the hematopoietic system [44,45]. Neuroinflammation is the brain's response to injury, infection, or disease. Although, initial immune or inflammatory response is to remove damaged tissue or to inactivate potentially damaging agents, 
over-activation of the system can have severe detrimental consequences including precipitation of depressive-like behavior. Thus, patients who have major depressive disorder show alterations in immunologic markers such as increases in pro-inflammatory cytokines (discussed below). Moreover, chronic low-grade inflammation may result in changes in brain structure and synaptic plasticity leading to neurodegeneration [46-49]. This, coupled with a reduction in neuroprotection, may not only exacerbate depression, but may also lead to dementia, particularly in older people [48,50]. Furthermore, research suggests that neuroinflammation is suppressed by norepinephrine (NE), and that NE uptake inhibitors' therapeutic efficacy in depression may be at least partially related to this mechanism [51]. Interestingly, Interferon- $\gamma(\mathrm{IFN}-\gamma)$, a cytokine that is critical for innate and adaptive immunity, induces the enzyme indoleamine 2,3-dioxygenase (IDO), which causes reduction in tryptophan availability, leading to a reduction in serotonin synthesis in the brain that has been implicated in depression [52].

\section{Cytokines}

Cytokines are a large family of small signaling proteins secreted from various cell types that elicit varied biological activities including induction of both anti- or pro-inflammatory responses. Anti-inflammatory cytokines are generally released to counteract the pro-inflammatory cytokines. This regulation helps limit damaging effects of prolonged or excess inflammation caused by the pro-inflammatory cytokines. However, cytokines dysregulation can lead to insufficient mediation or inhibition of normal immune reaction leading to disease manifestation including neurodegenerative diseases (e.g., PD) as well as major depression [53-58]. For example, interleukins (IL-1, IL-6), and TNF- $\alpha$ are released in response to various toxins such as lipopolysaccharide (LPS: a compound derived from membrane of gram-negative bacteria causing inflammatory-mediated damage) and typically cause a low-level inflammatory response to combat the insult $[59,60]$. However, these cytokines tend to have dual effects. For example, IL-6 may not only have a pro-inflammatory action [61,62], but may also act to attenuate or down-regulate synthesis of other pro-inflammatory cytokines (e.g., IFN- $\gamma$, IL-1, and TNF- $\alpha$ ) [59,63,64]. IL-1, and TNF- $\alpha$, as mentioned earlier also have acute pro-inflammatory actions, and dysregulation of production of one or more of these cytokines may precipitate a variety of neurological disorders including PD as well as MDD [65-68]. The mechanism of cytokine actions include impairment of neurogenesis and exacerbation of neuronal death [69-73] and may involve disruption of survival signaling pathways and caspase-dependent cascades, as well as alteration of normal receptor function [71-73].

\section{Parkinson's Disease}

\subsection{General Considerations}

Parkinson's Disease (PD), the second largest neurological illness in the elderly after Alzheimer's, may affect as many as 6.3 million people worldwide. This neurodegenerative neurological movement disorder mostly affects people over the age of 65 , however $15 \%$ of people can develop it before the age of 50. PD is a progressive neurodegenerative disorder that causes increased debilitating symptoms resulting from loss or damage to dopaminergic cells in the substantia nigra (SN). The causes for the development and progression of PD invariably involve an interaction between the person's environment 
and genetic disposition. In fact, many studies link PD with exposure to various endogenous (e.g., salsolinol) and exogenous toxins (e.g., MPTP = 1-methyl-4-phenyl-1,2,3,6-tetrahydropyridine) (reviewed by [74]). Therefore, these compounds are often used to create in vitro and in vivo models to study PD. Salsolinol is an endogenous neuromodulator in dopaminergic cells formed during the metabolism of dopamine [75]. Dysregulation of salsolinol, especially its $(R)$-enantiomer form in the brain, is thought to contribute to development of PD [76-79]. It has been proposed that salsolinol and its derivatives (e.g., norsalsolinol, N-methylnorsalsolinol, $\mathrm{N}$-methylsalsolinol) may serve as a marker for PD as they are increased in the cerebrospinal fluid [80] and the urine [81] of patients with PD. Exogenous compounds that are non-isoquinoline derivatives have also been shown to induce dopaminergic cell death in the SN. One such example is rotenone, a naturally occurring plant toxin that has been developed into a widely used pesticide and insecticide. Rotenone's toxicity has been demonstrated in various in vitro [82-84] and in vivo [85] studies. Moreover, it has been shown that when low doses of multiple exogenous factors are combined, a synergistic neurotoxicity may result. Thus, combination of nontoxic or minimally toxic concentrations of rotenone and LPS can result in exaggerated or synergistic toxicity [86]. Recently, we have provided in vitro evidence that exposure to a combination of salsolinol and rotenone can have synergistic toxicity. Moreover, we showed that pretreatment with curcumin can protect against such toxicity [87].

\subsection{PD and Inflammation}

As mentioned above, the immune system is designed to help protect the body against disease, toxic agents, stress, and injury. Inflammation is the first response to infection and injury as the body initiates a defense, mediated by cytokines towards the healing process. In a normal functioning system, pro- and anti-inflammatory cytokines function in a regulatory loop to maintain the proper response. However, breakdown of the normal response by factors such as stress or other insults can cause inflammation to become persistent and harmful [88]. For example, inflammation induced by LPS causes long-term increase in brain TNF- $\alpha$ from microglia months after it has subsided in the periphery [89]. This increased pro-inflammatory response may also induce a delayed and progressive loss in dopaminergic neurons in the substantia nigra, similar to that seen in PD suggesting that enhanced neuroinflammation could lead to PD [89-91]. In addition, the elevated levels of pro-inflammatory cytokines (e.g., IL-6 and IL-1 $\beta$ ) can induce symptoms of a syndrome termed "sickness behavior" [89,92,93], which include depression, reduction in locomotor activity, anhedonia, anorexia and cognitive disturbances [92-95]. In recent years, a number of findings have reinforced the idea that unregulated inflammation can lead to major depression and neurodegeneration. This contention is further supported by the findings that administration of high levels of pro-inflammatory cytokines can cause changes in behavior similar to depression and that attenuation of inflammatory response reduces depressive symptoms [96,97]. Thus, there is substantial support for inflammation as a common neurobiological substrate responsible for the co-morbid manifestation of neurodegenerative diseases (e.g., PD) and MDD. Curiously, it has been recently proposed that inflammation may also be the common mediator of commonly observed co-morbid conditions of depression and chronic pain [93]. 


\section{Role of Stress}

Stress is known to alter immune functioning [98]. Maes et al [98] were the first to show that psychological stressors in humans induce inflammatory responses through production of pro-inflammatory cytokines, such as IFN- $\gamma$ and TNF- $\alpha$. Subsequent studies have shown this to be true with a variety of other stressors as well $[99,100]$. Animal studies have also demonstrated that stressors increase cytokine levels such as IL-1beta and IL-6 in the blood and in various regions of the brain $[49,69,101,102]$. Goshen et al. [69] have specifically shown that after chronic mild stress normal mice show depressive-like behavior and an increase in IL-1 $\beta$ in the hippocampus. However, IL-1 receptor-deficient mice do not show such behavioral changes. Recently, it has been shown that direct administration of TNF- $\alpha$ can also induce a depressive-like state that can be blocked with the anti-TNF- $\alpha$ antibody [103]. Interestingly, it has been proposed that the action of some anti-depressants may also be attributed to a reduction in pro-inflammatory cytokines [97,104]. Moreover, neurological diseases like Alzheimer's disease [50,105], amyotrophic lateral sclerosis, epilepsy, Huntington's disease, multiple sclerosis, and PD [106] are often co-morbid with depression and express inflammatory markers. Thus, stress via enhanced release of pro-inflammatory cytokines such as TNF- $\alpha$, IL- $1 \beta$ and IL-6 may not only precipitate depression, but may also accelerate the neurodegenerative processes. For this reason drugs that may interfere with detrimental consequences of stress on inflammatory pathways may be of therapeutic potential in neurodegenerative and/or mood disorders.

Thus, direct effects of stress on inflammatory pathways, key proteins involved in signal transduction mechanisms as well as a variety of neurotrophic factors may be a common denominator to the detrimental consequences of chronic stress including induction and/or aggravation of neurodegenerative diseases as well as neuropsychiatric disorders including MDD.

\section{Curcumin: Antidepressant}

The above discussions have provided a framework for consideration of inflammation as an important player in the precipitation of depressive disorders. Hence, the well-documented anti-inflammatory effects of curcumin in in vitro and in vivo studies [107-110], including our own observation of its protective effects against LPS- and various cytokine-induced toxicity in SH-SY5Y cells [87] offer a mechanistic basis for observed antidepressant effects of curcumin. Indeed, numerous studies using various animal models of depression [14-16,111,112] including olfactory bulbectomized rat model of depression [113] as well as a recent report by us utilizing the WKY rats as a putative animal model of depression [19] provide solid evidence for an antidepressant effect of curcumin. Moreover, various clinical studies indicate therapeutic potential of curcumin in MDDs. These studies include randomized controlled trials of curcumin alone [114,115], or with piperine, an alkaloid found in black and long peppers, to boost the bioavailability of curcumin [116].

\section{Curcumin: Neuroprotectant}

Similarly, the role of neuro-inflammatory mediators as contributory factors to neurodegenerative diseases in general, and PD in particular, have been emphasized above. Numerous observations of the protective effects of curcumin against various inflammatory-mediated axonal or neuronal damage are 
all in line with its potential beneficial effects in treating neurodegenerative diseases including PD. For example, research shows its protection against: chronic inflammation associated with Alzheimer's disease [117]; axonal degeneration from local neuroinflammation [118]; $\beta$-amyloid induced degeneration [119]; peripheral neuropathy [120]; experimental models of Huntington's disease [121]; okadaic acid induced memory impairment in mice [122]; N-methyl N-nitrosourea induced functional and structural alterations in mice brain [123], as well as our own observation of its protective effects against damage induced by a combination of salsolinol and rotenone in neuroblastoma cell lines [87]. A survey of clinical studies on potential usefulness of curcumin in Alzheimer's disease [124,125]; dementia [126] and PD further support its potential therapeutic benefits [127,128].

\section{Conclusions}

Based on the above discussion, it is not unreasonable to suggest that the anti-inflammatory properties of curcumin are at least partially responsible for its antidepressant and its neuroprotectant effects. However, a few important points have to be considered in this regard. The first point concerns the bioavailability of curcumin as dietary curcumin exhibits poor bioavailability [129]. This might be due to several factors including its insolubility in water, poor absorption and rapid metabolism that need to be overcome for a more meaningful therapeutic intervention with curcumin. In this regard, it has been suggested that addition of piperine could enhance its absorption [116,129]. Moreover, the bioavailability of curcumin; may be increased by its dissolution in oil or cooking [130]. This is key in understanding the effects seen in the epidemiological studies [24-26], as curcumin, piperine, and oil are often used in combination in traditional Indian cooking. However, pharmacological structural modification and development of novel curcumin derivatives that may be administered orally or intra-nasally may offer a more realistic and potent therapeutic approach.

The other important point concerns possible combination of curcumin or its more stable derivatives with current or other medications to treat depression and/or PD. This approach may be particularly beneficial since different drugs may act at different sites and offer a better control of inflammatory and other processes (e.g., oxidation) that may contribute to the pathology of these diseases. In this regard, it is noteworthy that a number of novel compounds including nicotine, resveratrol, ketamine and more recently, estrogen receptor agonists, have shown potential usefulness in major depression and PD [131-133].

Finally, it is also of relevance to note that, in addition to the mechanisms mentioned above, curcumin might also affect a variety of other factors or mediators that have a direct role in neurodegenerative and/or mood regulating processes. To this end, it has been demonstrated that curcumin may affect: mitochondrial dysfunction [134]; oxidative stress [135]; molecular chaperones [136]; mTOR pathway [137] and MAPK expression [138]. Figure 1 provides some insight into few possible molecular mechanisms involved in neuroprotective and/or antidepressant effects of curcumin. These mechanisms warrant further research to understand their role in mediating the various actions that curcumin has in the brain.

In summary, novel compounds based on curcumin, alone or in combination with other known drugs that suppress inflammation and have been shown to exert antidepressant and/or neuroprotective effects may offer optimum therapy in major depression and PD. 
Figure 1. Potential Molecular Mechanisms Affected by Curcumin. The inhibition of cell signaling pathways such as Akt, NF-kB, or PI3K [139], has been suggested as the mechanism responsible for anticancer effects of curcumin. Curcumin may also inhibit the activity and synthesis of the enzymes implicated in inflammation such as cyclooxygenase-2 and 5-lipooxygenase. Moreover, its anti-inflammatory effect may be linked to inhibition of pro-inflammatory leukotrienes as well as to its neutrophil function $[63,64]$. Inhibition of TNF [59] may contribute to a physical interaction with other key signaling protein like BDNF that might enhance its antidepressant effect.
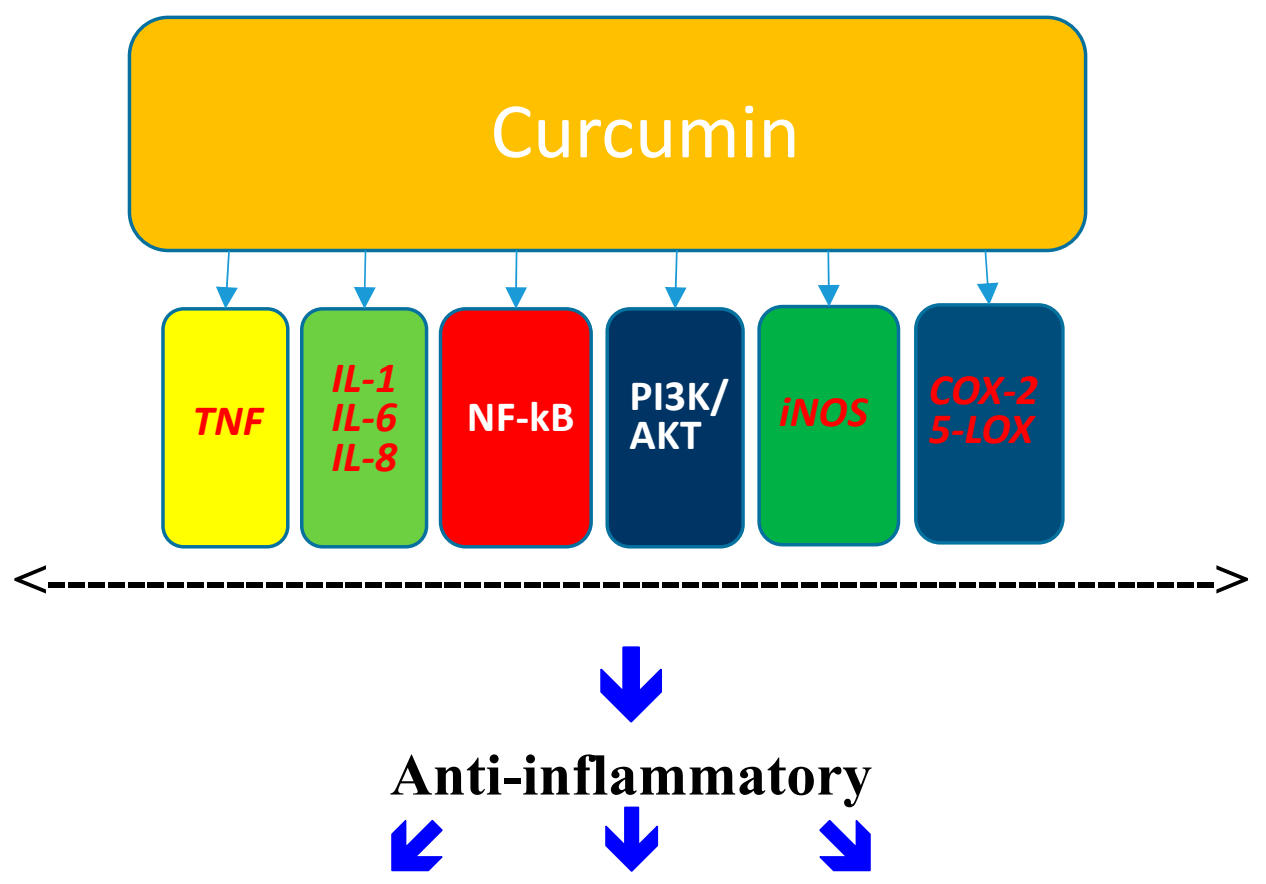

Anticancer

Antidepressant Neuroprotectant

\section{Acknowledgments}

This work was supported by a grant from NIH/NIAAA R03AA022479.

\section{Author Contributions}

YT in consultation with LH, LA and ZQ designed research. LH, ZQ and LA performed research and with YT analyzed the data. YT, LH, LA and ZQ wrote the paper. All authors read and approved the final manuscript.

\section{Conflicts of Interest}

The authors declare no conflict of interest.

\section{References}

1. Manolova, Y.; Deneva, V.; Antonov, L. The effect of the water on the curcumin tautomerism: A quantitative approach. Spectrochim. Acta A 2014, 132, 815-820. 
2. Sharma, O.P. Antioxidant activity of curcumin and related compounds. Biochem. Pharmacol. 1976, 25, 1811-1812.

3. Ruby, A.J.; Kuttan, G.; Babu, K.D.; Rajasekharan, K.N.; Kuttan, R. Anti-tumour and antioxidant activity of natural curcuminoids. Cancer Lett. 1995, 94, 79-83.

4. Sandur, S.K.; Ichikawa, H.; Pandey, M.K.; Kunnumakkara, A.B.; Sung, B.; Sethi, G.; Aggarwal, B.B. Role of pro-oxidants and antioxidants in the anti-inflammatory and apoptotic effects of curcumin (diferuloylmethane). Free Radic. Biol. Med. 2007, 43, 568-580.

5. Kiso, Y.; Suzuki, Y.; Watanabe, N.; Oshima, Y.; Hikino, H. Antihepatotoxic principles of Curcuma longa Rhizomes1. Planta Med. 1983, 49, 185-187.

6. Venkatesan, N.; Punithavathi, D.; Arumugam, V. Curcumin prevents adriamycin nephrotoxicity in rats. Br. J. Pharmacol. 2000, 129, 231-234.

7. Singh, R.; Sharma, P. Hepatoprotective effect of curcumin onlindane-induced oxidative stress in male Wistar rats. Toxicol. Int. 2011, 18, 124-129.

8. De, R.; Kundu, P.; Swarnakar, S.; Ramamurthy, T.; Chowdhury, A.; Nair, G.B.; Mukhopadhyay, A.K. Antimicrobial activity of curcumin against Helicobacter pylori isolates from India and during infections in mice. Antimicrob. Agents Chemother. 2009, 53, 1592-1597.

9. Wang, Y.; Lu, Z.; Wu, H.; Lv, F. Study on the antibiotic activity of microcapsule curcumin against foodborne pathogens. Int. J. Food Microbiol. 2009, 136, 71-74.

10. Sandur, S.K.; Pandey, M.K.; Sung, B.; Ahn, K.S.; Murakami, A.; Sethi, G.; Limtrakul, P.; Badmaev, V.; Aggarwal, B.B. Curcumin, demethoxycurcumin, bisdemethoxycurcumin, tetrahydrocurcumin and turmerones differentially regulate anti-inflammatory and anti-proliferative responses through a ROS-independent mechanism. Carcinogenesis 2007, 28, 1765-1773.

11. Aggarwal, B.B.; Harikumar, K.B. Potential therapeutic effects of curcumin, the anti-inflammatory agent, against neurodegenerative, cardiovascular, pulmonary, metabolic, autoimmune and neoplastic diseases. Int. J. Biochem. Cell Biol. 2009, 41, 40-59.

12. Jurenka, J.S. Anti-inflammatory properties of curcumin, a major constituent of Curcuma longa: A review of preclinical and clinical research. Altern. Med. Rev. 2009, 14, 141-153.

13. Tripanichkul, W.; Jaroensuppaperch, E.O. Ameliorating effects of curcumin on 6-OHDA-induced dopaminergic denervation, glial response, and SOD1 reduction in the striatum of hemiparkinsonian mice. Eur. Rev. Med. Pharmacol. Sci. 2013, 10, 1360-1368.

14. Xu, Y.; Ku, B.S.; Yao, H.Y.; Lin, Y.H.; Ma, X.; Zhang, Y.H.; Li, X.J. Antidepressant effects of curcumin in the forced swim test and olfactory bulbectomy models of depression in rats. Pharmacol. Biochem. Behav. 2005, 82, 200-206.

15. Kulkarni, S.K.; Bhutani, M.K.; Bishnoi, M. Antidepressant activity of curcumin: Involvement of serotonin and dopamine system. Psychopharmacology 2008, 201, 435-442.

16. Bhutani, M.K.; Bishnoi, M.; Kulkarni, S.K. Anti-depressant like effect of curcumin and its combination with piperine in unpredictable chronic stress-induced behavioral, biochemical and neurochemical changes. Pharmacol. Biochem. Behav. 2009, 92, 39-43.

17. Li, Y.C.; Wang, F.M.; Pan, Y.; Qiang, L.Q.; Cheng, G.; Zhang, W.Y.; Kong, L.D. Antidepressant-like effects of curcumin on serotonergic receptor-coupled AC-cAMP pathway in chronic unpredictable mild stress of rats. Prog. Neuropsychopharmacol. Biol. Psychiatry 2009, 33, 435-449. 
18. Arora, V.; Kuhad, A.; Tiwari, V.; Chopra, K. Curcumin ameliorates reserpine-induced pain depression dyad: Behavioural, neurochemical and molecular evidences. Psychoneuroendocrinology 2011, 36, 1570-1581.

19. Hurley, L.L.; Akinfiresoye, L.; Nwulia, E.; Kamiya, A.; Kulkarni, A.A.; Tizabi, Y. Antidepressant-like effects of curcumin in WKY rat model of depression is associated with an increase in hippocampal BDNF. Behav. Brain Res. 2013, 239, 27-30.

20. Chandra, V.; Pandav, R.; Dodge, H.H.; Johnston, J.M.; Belle, S.H.; DeKosky, S.T.; Ganguli, M. Incidence of Alzheimer's disease in a rural community in India: The Indo-US study. Neurology 2001, 57, 985-989.

21. Vas, C.J.; Pinto, C.; Panikker, D.; Noronha, S.; Deshpande, N.; Kulkarni, L.; Sachdeva, S. Prevalence of dementia in an urban Indian population. Int. Psychogeriatr. 2001, 13, 439-450.

22. Ng, T.P.; Chiam, P.C.; Lee, T.; Chua, H.C.; Lim, L.; Kua, E.H. Curry consumption and cognitive function in the elderly. Am. J. Epidemiol. 2006, 164, 898-906.

23. Aggarwal, B.B.; Sundaram, C.; Malani, N.; Ichikawa, H. Curcumin: The Indian solid gold. Adv. Exp. Med. Biol. 2007, 595, 1-75.

24. Muthane, U.;Yasha, T.C.; Shankar, S.K. Low numbers and no loss of melanized nigral neurons with increasing age in normal human brains from India. Ann. Neurol. 1998, 43, 283-287.

25. Alladi, P.A.; Mahadevan, A.; Yasha, T.C.; Raju, T.R.; Shankar, S.K.; Muthane, U. Absence of age-related changes in nigral dopaminergic neurons of Asian Indians: Relevance to lower incidence of Parkinson's disease. Neuroscience 2009, 159, 236-245.

26. Darvesh, A.S.; Carroll, R.T.; Bishayee, A.; Novotny, N.A.; Geldenhuys, W.J.; Van der Schyf, C.J. Curcumin and neurodegenerative diseases: A perspective. Expert Opin. Investig. Drugs 2012, 21, 1123-1140.

27. Baumeister, H.; Harter, M. Prevalence of mental disorders based on general population surveys. Soc. Psychiatry Psychiatr. Epidemiol. 2007, 42, 537-546.

28. Rush, A.J.; Thase, M.E.; Dube, S. Research issues in the study of difficult-to-treat depression. Biol. Psychiatry 2003, 53, 743-753.

29. Rush, A.j.; Trivedi, M.H.; Wisniewski, S.R.; Nierenberg, A.A.; Stewart, J.W.; Warden, D. Acute and longer-term outcomes in depressed outpatients requiring one or several treatment steps: A STAR*D report. Am. J. Psychiatry 2006, 163, 1905-191.

30. Duman, R.S.; Malberg, J.; Nakagawa, S.; D’Sa, C. Neuronal plasticity and survival in mood disorders. Biol. Psychiatry 2000, 48, 732-739.

31. Manji, H.K.; Duman, R.S. Impairments of neuroplasticity and cellular resilience in severe mood disorders: Implications for the development of novel therapeutics. Psychopharmacol. Bull. 2001, 35, 5-49.

32. Lee, A.L.; Ogle, W.O.; Sapolsky, R.M. Stress and depression: Possible links to neuron death in the hippocampus. Bipolar Disord. 2002, 4, 117-128.

33. Shah, P.J.; Glabus, M.F.; Goodwin, G.M.; Ebmeier, K.P. Chronic, treatment-resistant depression and right fronto-striatal atrophy. Br. J. Psychiatry 2002, 180, 434-440.

34. Banasr, M.; Chowdhury, G.M.; Terwilliger, R.; Newton, S.S.; Duman, R.S.; Behar, K.L. Glial pathology in an animal model of depression: Reversal of stress-induced cellular, metabolic and behavioral deficits by the glutamate-modulating drug riluzole. Mol. Psychiatry 2010, 15, 501-511. 
35. Banasr, M.; Dwyer, J.M.; Duman, R.S. Cell atrophy and loss in depression: Reversal by antidepressant treatment. Curr. Opin. Cell Biol. 2011, 23, 730-737.

36. Feng, P.; Guan, Z.; Yang, X.; Fang, J. Impairments of ERK signal transduction in the brain in a rat model of depression induced by neonatal exposure of clomipramine. Brain Res. 2003, 991, 195-205.

37. Drzyzga, L.R.; Marcinowska, A.; Obuchowicz, E. Antiapoptotic and neurotrophic effects of antidepressants: A review of clinical and experimental studies. Brain Res. Bull. 2009, 79, 248-257.

38. Yaniv, S.P.; Lucki, A.; Klein, E.; Ben-Shachar, D. Dexamethasone enhances the norepinephrine-induced ERK/MAPK intracellular pathway possibly via dysregulation of the a2-adrenergic receptor: Implications for antidepressant drug mechanism of action. Eur. J. Cell Biol. 2010, 89, 712-722.

39. Wolkowitz, O.M.; Mellon, S.H.; Epel, E.S.; Lin, J.; Dhabar, F.S.; Su, Y.; Blackburn, E.H. Leukocyte telomere length in major depression: Correlations with chronicity, inflammation and oxidative stress-Preliminary findings. PLoS One 2011, 6, e17837.

40. Yasui-Furukori, N.; Tsuchimine, S.; Nakagami, T.; Fujii, A.; Sato, Y.; Tomita, T.; Yoshizawa, K.; Inoue, Y.; Kaneko, S. Association between plasma paroxetine concentration and changes in plasma brain-derived neurotrophic factor levels in patients with major depressive disorder. Hum. Psychopharmacol. 2011, 26, 194-200.

41. Krishnan, V.; Nestler, E.J. The molecular neurobiology of depression. Nature 2008, 455, 894-902.

42. Yang, D.; Li, Q.; Fang, L.; Cheng, K.; Zhang, R.; Zheng, P.; Zhan, Q.; Qi, Z.; Zhong, S.; Xie, P. Reduced neurogenesis and pre-synaptic dysfunction in the olfactory bulb of a rat model of depression. Neuroscience 2011, 192, 609-618.

43. Malberg, J.E.; Eisch, A.J.; Nestler, E.J.; Duman, R.S. Chronic antidepressant treatment increases neurogenesis in adult rat hippocampus. J. Neurosci. 2000, 20, 9104-9110.

44. Streit, W.J.; Walter, S.A.; Pennell, N.A. Reactive microgliosis. Prog. Neurobiol. 1999, 57, 563-581.

45. Stoll, G.; Jander, S. The role of microglia and macrophages in the pathophysiology of the CNS. Prog. Neurobiol. 1999, 58, 233-247.

46. Hayley, S.; Poulter, M.O.; Merali, Z.; Anisman, H. The pathogenesis of clinical depression: Stressor- and cytokine-induced alterations of neuroplasticity. Neuroscience 2005, 135, 659-678.

47. Khairova, R.A.; Machado-Vieira, R.; Du, J.; Manji, H.K. A potential role for pro-inflammatory cytokines in regulating synaptic plasticity in major depressive disorder. Int. J. Neuropsychopharmacol. 2009, 12, 561-578.

48. Leonard, B.E. Inflammation, depression and dementia: Are they connected? Neurochem. Res. 2007, 32, 1749-1756.

49. Maes, M.; Yirmyia, R.; Noraberg, J.; Brene, S.; Hibbeln, J.; Perini, G.; Kubera, M.; Bob, P.; Lerer, B.; Maj, M. The inflammatory \& neurodegenerative (I\&ND) hypothesis of depression: Leads for future research and new drug developments in depression. Metab. Brain Dis. 2009, 24, 27-53.

50. Leonard, B.E.; Myint, A. The psychoneuroimmunology of depression. Hum. Psychopharmacol. 2009, 24, 165-175.

51. O’Sullivan, J.B.; Ryan, K.M.; Curtin, N.M.; Harkin, A.; Connor, T.J. Noradrenaline reuptake inhibitors limit neuroinflammation in rat cortex following a systemic inflammatory challenge: Implications for depression and neurodegeneration. Int. J. Neuropsychopharmacol. 2009, 12, 687-699. 
52. Wirleitner, B.; Neurauter, G.; Schrocksnadel, K.; Frick, B.; Fuchs, D. Interferon- $\gamma$-induced conversion of tryptophan: Immunologic and neuropsychiatric aspects. Curr. Med. Chem. 2003, 10, 1581-1591.

53. Dinarello, C.A. Role of pro- and anti-inflammatory cytokines during inflammation: Experimental and clinical findings. J. Biol. Regul. Homeost. Agents 1997, 11, 91-103.

54. Dinarello, C.A. Interleukin-1, interleukin-1 receptors and interleukin-1 receptor antagonist. Int. Rev. Immunol. 1998, 16, 457-499.

55. Gold, S.M.; Irwin, M.R. Depression and immunity: Inflammation and depressive symptoms in multiple sclerosis. Immunol. Allergy Clin. North Am. 2009, 29, 309-320.

56. Kasai, T.; Inada, K.; Takakuwa, T.; Yamada, Y.; Inoue, Y.; Shimamura, T.; Taniguchi, S.; Sato, S.; Wakabayashi, G.; Endo, S. Anti-inflammatory cytokine levels in patients with septic shock. Res. Commun. Mol. Pathol. Pharmacol. 1997, 98, 34-42.

57. Munoz, C.; Carlet, J.; Fitting, C.; Misset, B.; Bleriot, J.P.; Cavaillon, J.M. Dysregulation of in vitro cytokine production by monocytes during sepsis. J. Clin. Investig. 1991, 88, 1747-1754.

58. Rubio-Perez, J.M.; Morillas-Ruiz, J.M. A review: Inflammatory process in Alzheimer's disease, role of cytokines. Sci. World J. 2012, 2012, doi:10.1100/2012/756357.

59. Barton, BE. IL-6: Insights into novel biological activities. Clin. Immunol. Immunopathol. 1997, 85, $16-20$.

60. Zhang, F.; Wang, H.; Wu, Q.; Lu, Y.; Nie, J.; Xie, X.; Shi, J. Resveratrol Protects Cortical Neurons against Microglia-mediated Neuroinflammation. Phytother. Res. 2013, 27, 244-249.

61. Barton, B.E.; Shortall, J.; Jackson, J.V. Interleukins 6 and 11 protect mice from mortality in a staphylococcal enterotoxin-induced toxic shock model. Infect. Immun. 1996, 64, 714-718.

62. Hurst, S.M.; Wilkinson, T.S.; McLoughlin, R.M.; Jones, S.; Horiuchi, S.; Yamamoto, N.; Rose-John, S.; Fuller, G.M.; Topley, N.; Jones, S.A. Il-6 and its soluble receptor orchestrate a temporal switch in the pattern of leukocyte recruitment seen during acute inflammation. Immunity 2001, 14, 705-714.

63. Libert, C.; Takahashi, N.; Cauwels, A.; Brouckaert, P.; Bluethmann, H.; Fiers, W. Response of interleukin-6-deficient mice to tumor necrosis factor-induced metabolic changes and lethality. Eur. J. Immunol. 1994, 24, 2237-2242.

64. Xing, Z.; Gauldie, J.; Cox, G.; Baumann, H.; Jordana, M.; Lei, X.F.; Achong, M.K. IL-6 is an antiinflammatory cytokine required for controlling local or systemic acute inflammatory responses. J. Clin. Investig. 1998, 101, 311-320.

65. Swardfager, W.; Lanctot, K.; Rothenburg, L.; Wong, A.; Cappell, J.; Herrmann, N. A meta-analysis of cytokines in Alzheimer's disease. Biol. Psychiatry 2010, 68, 930-941.

66. Nagatsu, T.; Mogi, M.; Ichinose, H.; Togari, A. Changes in cytokines and neurotrophins in Parkinson's disease. J. Neural. Transm. Suppl. 2000, 60, 277-290.

67. Dowlati, Y.; Herrmann, N.; Swardfager, W.; Liu, H.; Sham, L.; Reim, E.K.; Lanctot, K.L. A meta-analysis of cytokines in major depression. Biol. Psychiatry 2010, 67, 446-457.

68. Howren, M.B.; Lamkin, D.M.; Suls, J. Associations of depression with C-reactive protein, IL-1, and IL-6: A meta-analysis. Psychosom. Med. 2009, 71, 171-186. 
69. Goshen, I.; Kreisel, T.; Ben-Menachem-Zidon, O.; Licht, T.; Weidenfeld, J.; Ben-Hur, T.; Yirmiya, R. Brain interleukin-1 mediates chronic stress-induced depression in mice via adrenocortical activation and hippocampal neurogenesis suppression. Mol. Psychiatry 2008, 13, 717-728.

70. Koo, J.W.; Duman, R.S. IL-1 $\beta$ is an essential mediator of the antineurogenic and anhedonic effects of stress. Proc. Natl. Acad. Sci. USA 2008, 105, 751-756.

71. Patel, H.C.; Ross, F.M.; Heenan, L.E.; Davies, R.E.; Rothwell, N.J.; Allan, S.M. Neurodegenerative actions of interleukin-1 in the rat brain are mediated through increases in seizure activity. J. Neurosci. Res. 2006, 83, 385-391.

72. Viviani, B.; Bartesaghi, S.; Corsini, E.; Galli, C.L.; Marinovich, M. Cytokines role in neurodegenerative events. Toxicol. Lett. 2004, 149, 85-89.

73. Zou, J.Y.; Crews, F.T. TNF a potentiates glutamate neurotoxicity by inhibiting glutamate uptake in organotypic brain slice cultures: Neuroprotection by NF kappa B inhibition. Brain Res. 2005, $1034,11-24$.

74. Tieu, K. A guide to neurotoxic animal models of Parkinson's disease. Cold Spring Harb. Perspect. Med. 2011, 1, doi:10.1101/cshperspect.a009316.

75. Mravec, B. Salsolinol, a derivate of dopamine, is a possible modulator of catecholaminergic transmission: A review of recent developments. Physiol. Res. 2006, 55, 353-364.

76. Dostert, P.; Strolin Benedetti, M.; Dordain, G. Dopamine-derived alkaloids in alcoholism and in Parkinson's and Huntington's diseases. J. Neural Transm. 1988, 74, 61-74.

77. Nagatsu, T. Isoquinoline neurotoxins in the brain and Parkinson's disease. Neurosci. Res. 1997, 29, 99-111.

78. Naoi, M.; Maruyama, W.; Matsubara, K.; Hashizume, Y. A neutral $N$-methyltransferase activity in the striatum determines the level of an endogenous $\mathrm{MPP}^{+}$-like neurotoxin, 1,2-dimethyl-6,7dihydroxyisoquinolinium ion, in the substantia nigra of human brains. Neurosci. Lett. 1997, 235, 81-84.

79. Antkiewicz-Michaluk, L. Endogenous risk factors in Parkinson's disease: Dopamine and tetrahydroisoquinolines. Pol. J. Pharmacol. 2002, 54, 567-572.

80. Maruyama, W.; Dostert, P.; Matsubara, K.; Naoi, M. N-methyl(R)salsolinol produces hydroxyl radicals: Involvement to neurotoxicity. Free Radic. Biol. Med. 1995, 19, 67-75.

81. Moser, A.; Siebecker, F.; Vieregge, P.; Jaskowski, P.; Kompf, D. Salsolinol, catecholamine metabolites, and visual hallucinations in L-dopa treated patients with Parkinson's disease. J. Neural Transm. 1996, 103, 421-432.

82. Hartley, A.; Stone, J.M.; Heron, C.; Cooper, J.M.; Schapira, A.H. Complex I inhibitors induce dose-dependent apoptosis in PC12 cells: Relevance to Parkinson's disease. J. Neurochem. 1994, 63, 1987-1990.

83. Gao, H.M.; Hong, J.S.; Zhang, W.; Liu, B. Distinct role for microglia in rotenone-induced degeneration of dopaminergic neurons. J. Neurosci. 2002, 22, 782-790.

84. Freestone, P.S.; Chung, K.K.; Guatteo, E.; Mercuri, N.B.; Nicholson, L.F.; Lipski, J. Acute action of rotenone on nigral dopaminergic neurons - involvement of reactive oxygen species and disruption of $\mathrm{Ca}^{2+}$ homeostasis. Eur. J. Neurosci. 2009, 30, 1849-1859. 
85. Caboni, P.; Sherer, T.B.; Zhang, N.; Taylor, G.; Na, H.M.; Greenamyre, J.T.; Casida, J.E. Rotenone, deguelin, their metabolites, and the rat model of Parkinson's disease. Chem. Res. Toxicol. 2004, 17, $1540-1548$.

86. Gao, H.M.; Hong, J.S.; Zhang, W.; Liu, B. Synergistic dopaminergic neurotoxicity of the pesticide rotenone and inflammogen lipopolysaccharide: Relevance to the etiology of Parkinson's disease. J. Neurosci. 2003, 23, 1228-1236.

87. Qualls, Z.; Brown, D.; Ramlochansingh, C.; Hurley, L.L.; Tizabi, Y. Protective effects of curcumin against rotenone and salsolinol-induced toxicity: Implications for Parkinson's disease. Neurotox. Res. 2014, 25, 81-89.

88. Gao, H.M.; Hong, J.S. Why neurodegenerative diseases are progressive: Uncontrolled inflammation drives disease progression. Trends Immunol. 2008, 29, 357-365.

89. Qin, L.; Wu, X.; Block, M.L.; Liu, Y.; Breese, G.R.; Hong, J.S.; Knapp, D.J.; Crews, F.T. Systemic LPS causes chronic neuroinflammation and progressive neurodegeneration. Glia 2007, 55, 453-462.

90. Kannarkat, G.T.; Boss, J.M.; Tansey, M.G. The role of innate and adaptive immunity in Parkinson's disease. J. Parkinson's Dis. 2013, 4, 493-514.

91. Russo, I.; Bubacco, L.; Greggio, E. LRRK2 and neuroinflammation: Partners in crime in Parkinson's disease? J. Neuroinflam. 2014, 21, 11-52.

92. Kent, S.; Bluthe, R.M.; Kelley, K.W.; Dantzer, R. Sickness behavior as a new target for drug development. Trends Pharmacol. Sci. 1992, 13, 24-28.

93. Walker, D.G.; Lue, L.F.; Adler, C.H.; Shill, H.A.; Caviness, J.N.; Sabbagh, M.N.; Akiyama, H.; Serrano, G.E.; Sue, L.I.; Beach, T.G. Changes in properties of serine 129 phosphorylated $\alpha$-synuclein with progression of Lewy-type histopathology in human brains. Exp. Neurol. 2013, 240, 190-204.

94. Maes, M.; Bosmans, E.; Meltzer, H.Y.; Scharpe, S.; Suy, E. Interleukin-1ß: A putative mediator of HPA axis hyperactivity in major depression? Am. J. Psychiatry 1993, 150, 1189-1193.

95. Yirmiya, R.; Barak, O.; Avitsur, R.; Gallily, R.; Weidenfeld, J. Intracerebral administration of Mycoplasma fermentans produces sickness behavior: Role of prostaglandins. Brain Res. 1997, 749, 71-81.

96. Capuron, L.; Miller, A.H. Cytokines and psychopathology: Lessons from interferon- $\alpha$. Biol. Psychiatry 2004, 56, 819-824.

97. Pollak, Y.; Yirmiya, R. Cytokine-induced changes in mood and behaviour: Implications for "depression due to a general medical condition", immunotherapy and antidepressive treatment. Int. J. Neuropsychopharmacol. 2002, 5, 389-399.

98. Maes, M.; Song, C.; Lin, A.; de Jongh, R.; van Gastel, A.; Kenis, G.; Bosmans, E.; de Meester, I.; Benoy, I.; Neels, H.; et al. The effects of psychological stress on humans: Increased production of pro-inflammatory cytokines and a Th1-like response in stress-induced anxiety. Cytokine 1998, 10, 313-318.

99. Shapira-Lichter, I.; Beilin, B.; Ofek, K.; Bessler, H.; Gruberger, M.; Shavit, Y.; Seror, D.; Grinevich, G.; Posner, E.; Reichenberg, A.; et al. Cytokines and cholinergic signals co-modulate surgical stress-induced changes in mood and memory. Brain Behav. Immun. 2008, 22, 388-398. 
100. Steptoe, A.; Hamer, M.; Chida, Y. The effects of acute psychological stress on circulating inflammatory factors in humans: A review and meta-analysis. Brain Behav. Immun. 2007, 21, 901-912.

101. Ishikawa, I.; Kitamura, H.; Kimura, K.; Saito, M. Brain interleukin-1 is involved in blood interleukin-6 response to immobilization stress in rats. Jpn. J. Vet. Res. 2001, 49, 19-25.

102. Nguyen, K.T.; Deak, T.; Owens, S.M.; Kohno, T.; Fleshner, M.; Watkins, L.R.; Maier, S.F. Exposure to acute stress induces brain interleukin-1 $\beta$ protein in the rat. J. Neurosci. 1998, 18, 2239-2246.

103. Kaster, M.P.; Gadotti, V.M.; Calixto, J.B.; Santos, A.R.; Rodrigues, A.L. Depressive-like behavior induced by tumor necrosis factor- $\alpha$ in mice. Neuropharmacology 2012, 62, 419-426.

104. Zunszain, P.A.; Hepgul, N.; Pariante, C.M. Inflammation and Depression. Curr. Top. Behav. Neurosci. 2013, 14, 135-151.

105. Wuwongse, S.; Chang, R.C.; Law, A.C. The putative neurodegenerative links between depression and Alzheimer's disease. Prog. Neurobiol. 2010, 91, 362-375.

106. Hemmerle, A.M.; Herman, J.P.; Seroogy, K.B. Stress, depression and Parkinson's disease. Exp. Neurol. 2012, 233, 79-86.

107. Aggarwal, B.; Gupta, S.C.; Sung, B. Curcumin: An orally bioavailable blocker of TNF and other pro-inflammatory biomarkers. Br. J. Pharmacol. 2013, 169, 1672-1692.

108. Anthwal, A.; Thakur, B.K.; Rawat, M.S.; Rawat, D.S.; Tyagi, A.K.; Aggarwal, B.B. Synthesis, characterization and in vitro anticancer activity of C-5 curcumin analogues with potential to inhibit TNF- $\alpha$-induced NF- $\kappa B$ activation. Biomed. Res. Int. 2014, doi:10.1155/2014/524161.

109. Akbik, D.; Ghadiri, M.; Chrzanowski, W.; Rohanizadeh, R. Curcumin as a wound healing agent. Life Sci. 2014, 116, 1-7.

110. Witkin, J.M.; Li, X. Curcumin, an active constituent of the ancient medicinal herb Curcuma longa L.: Some uses and the establishment and biological basis of medical efficacy. CNS Neurol. Disord. Drug Targets 2013, 12, 487-497.

111. Wang, R.; Xu, Y.; Wu, H.L.; Li, Y.B.; Li, Y.H.; Guo, J.B. The antidepressant effects of curcumin in the forced swimming test involve 5-HT1 and 5-HT2 receptors. Eur. J. Pharmacol. 2008, 578, 43-50.

112. Xu, Y.; Ku, B.S.; Yao, H.Y.; Lin, Y.H.; Ma, X.; Zhang, Y.H. The effects of curcumin on depressive-like behaviors in mice. Eur. J. Pharmacol. 2005, 518, 40-46.

113. Borre, Y.E.; Panagaki, T.; Koelink, P.J.; Morgan, M.E.; Hendriksen, H.; Garssen, J.; Kraneveld, A.D.; Olivier, B.; Oosting, R.S. Neuroprotective and cognitive enhancing effects of a multi-targeted food intervention in an animal model of neurodegeneration and depression. Neuropharmacology 2014, 79, 738-749.

114. Lopresti, A.L.; Maes, M.; Maker, G.L.; Hood, S.D.; Drummond, P.D. Curcumin for the treatment of major depression: A randomised, double-blind, placebo controlled study. J. Affect. Disord. 2014, 167, 368-375.

115. Sanmukhani, J.; Satodia, V.; Trivedi, J.; Patel, T.; Tiwari, D.; Panchal, B.; Goel, A.; Tripathi, C.B. Efficacy and safety of curcumin in major depressive disorder: A randomized controlled trial. Phytother. Res. 2014, 28, 579-585. 
116. Panahi, Y.; Badeli, R.; Karami, G.R.; Sahebkar, A. Investigation of the Efficacy of Adjunctive Therapy with Bioavailability-Boosted Curcuminoids in Major Depressive Disorder. Phytother. Res. 2014, doi:10.1002/ptr.5211.

117. Millington, C.; Sonego, S.; Karunaweera, N.; Rangel, A.; Aldrich-Wright, J.R.; Campbell, I.L.; Gyengesi, E.; Münch, G. Chronic neuroinflammation in Alzheimer's disease: New perspectives on animal models and promising candidate drugs. Biomed. Res. Int. 2014, 2014, doi:10.1155/2014/309129.

118. Tegenge, M.A.; Rajbhandari, L.; Shrestha, S.; Mithal, A.; Hosmane, S.; Venkatesan, A. Curcumin protects axons from degeneration in the setting of local neuroinflammation. Exp. Neurol. 2014, 253, 102-110.

119. Wang, Y.; Yin, H.; Li, J.; Zhang, Y.; Han, B.; Zeng, Z.; Qiao, N.; Cui, X.; Lou, J.; Li, J. Amelioration of $\beta$-amyloid-induced cognitive dysfunction and hippocampal axon degeneration by curcumin is associated with suppression of CRMP-2 hyperphosphorylation. Neurosci. Lett. 2013, $557,112-117$.

120. Di Pierro, F.; Settembre, R. Safety and efficacy of an add-on therapy with curcumin phytosome and piperine and/or lipoic acid in subjects with a diagnosis of peripheral neuropathy treated with dexibuprofen. J. Pain Res. 2013, 6, 497-503.

121. Sandhir, R.; Yadav, A.; Mehrotra, A.; Sunkaria, A.; Singh, A.; Sharma, S. Curcumin nanoparticles attenuate neurochemical and neurobehavioral deficits in experimental model of Huntington's disease. Neuromolecular Med. 2014, 16, 106-118.

122. Rajasekar, N.; Dwivedi, S.; Tota, S.K.; Kamat, P.K.; Hanif, K.; Nath, C.; Shukla, R. Neuroprotective effect of curcumin on okadaic acid induced memory impairment in mice. Eur. J. Pharmacol. 2013, 715, 381-394.

123. Singula, N.; Chawan, D.K. N-methyl N-nitrosourea induced functional and structural alterations in mice brain-role of curcumin. Neurotox. Res. 2012, 22, 115-126.

124. Hamaguchi, T.; Ono, K.; Yamada, M. Review: Curcumin and Alzheimer's disease. CNS Neurosci. Ther. 2010, 16, 285-297.

125. Yang, C.; Su, X.; Liu, A.; Zhang, L.; Yu, A.; Xi, Y.; Zhai, G. Advances in clinical study of curcumin. Curr. Pharm. Des. 2013, 19, 1966-1973.

126. Brondino, N.; Re, S.; Boldrini, A.; Cuccomarino, A.; Lanati, N.; Barale, F.; Politi, P. Curcumin as a therapeutic agent in dementia: A mini systematic review of human studies. Sci. World J. 2014, 2014, doi:10.1155/2014/174282.

127. Mythri, R.; Bharath, M.M. Curcumin: A potential neuroprotective agent in Parkinson's disease. Curr. Pharm. Des. 2012, 18, 91-99.

128. Seidl, S.E.; Potashkin, J.A. The promise of neuroprotective agents in Parkinson's disease. Front. Neurol. 2011, 2, doi:10.3389/fneur.2011.00068.

129. Anand, P.; Kunnumakkara, A.B.; Newman, R.A.; Aggarwal, B.B. Bioavailability of curcumin: Problems and promises. Mol. Pharm. 2007, 6, 807-818.

130. Marczylo, T.H.; Verschoyle, R.D.; Cooke, D.N.; Morazzoni, P.; Steward, W.P.; Gescher, A.J. Comparison of systemic availability of curcumin with that of curcumin formulated with phosphatidylcholine. Cancer Chemother. Pharmacol. 2007, 60, 171-177. 
131. Hurley, L.L.; Tizabi, Y. Neuroinflammation, neurodegeneration, and depression. Neurotox. Res. 2013, 23, 131-144.

132. Akinfiresoye, L.; Tizabi, Y. Antidepressant effects of AMPA and ketamine combination: Role of hippocampal BDNF, synapsin, and mTOR. Psychopharmacology 2013, 230, 291-298.

133. Chakrabarti, M.; Haque, A.; Banik, N.L.; Nagarkatti, P.; Nagarkatti, M.; Ray, S.K. Estrogen receptor agonists for attenuation of neuroinflammation and neurodegeneration. Brain Res. Bull. 2014, 109, 22-31.

134. Banji, O.J.; Banji, D.; Ch, K. Curcumin and hesperidin improve cognition by suppressing mitochondrial dysfunction and apoptosis induced by D-galactose in rat brain. Food Chem. Toxicol. 2014, 74, 51-59.

135. Anderson, G.; Maes, M. Oxidative/nitrosative stress and immuno-inflammatory pathways in depression: Treatment implications. Curr. Pharm. Des. 2014, 20, 3812-3847.

136. Maiti, P.; Manna, J.; Veleri, S.; Frautschy, S. Molecular Chaperone Dysfunction in Neurodegenerative Diseases and Effects of Curcumin. Biomed. Res. Int. 2014, 2014, doi:10.1155/2014/495091.

137. Wang, C.; Zhang, X.; Teng, Z.; Zhang, T.; Li, Y. Downregulation of PI3K/Akt/mTOR signaling pathway in curcumin-induced autophagy in APP/PS1 double transgenic mice. Eur. J. Pharmacol. 2014, 740, 312-320.

138. Meesarapee, B.; Thampithak, A.; Jaisin, Y.; Sanvarinda, P.; Suksamrarn, A.; Tuchinda, P.; Morales, N.P.; Sanvarinda, Y. Curcumin I mediates neuroprotective effect through attenuation of quinoprotein formation, p-p38 MAPK expression, and caspase-3 activation in 6-hydroxydopamine treated SH-SY5Y cells. Phytother. Res. 2014, 28, 611-616.

139. Sun, Z.J.; Chen, G.; Zhang, W.; Hu, X.; Liu, Y.; Zhou, Q.; Zhu, L.X.; Zhao, Y.F. Curcumin dually inhibits both mammalian target of rapamycin and nuclear factor- $\kappa \mathrm{B}$ pathways through a crossed phosphatidylinositol 3-kinase/Akt/IкB kinase complex signaling axis in adenoid cystic carcinoma. Mol. Pharmacol. 2011, 79, 106-118.

(C) 2014 by the authors; licensee MDPI, Basel, Switzerland. This article is an open access article distributed under the terms and conditions of the Creative Commons Attribution license (http://creativecommons.org/licenses/by/4.0/). 